\title{
Article
}

\section{BIM Approach in Construction Safety - A Case Study}

\author{
Fernanda Rodrigues ${ }^{1 *}$, J. Santos Baptista ${ }^{2}$ and Débora Pinto ${ }^{3}$
}

1 RISCO, Civil Engineering Department, University of Aveiro, Portugal; mfrodrigues@ua.pt

2 Associated Laboratory for Energy, Transports and Aeronautics (PROA/LAETA), Faculty of Engineering, University of Porto, Portugal; jsbap@ fe.up.pt

3 Associated Laboratory for Energy, Transports and Aeronautics (PROA/LAETA), Faculty of Engineering, University of Porto, Portugal; deborasuelip@gmail.com

* Correspondence: mfrodrigues@ua.pt

\begin{abstract}
As is known, the construction industry has one of the highest occupational accidents incidence rates among all economic sectors. Currently, Building Information Modeling (BIM) appears as a tool that addresses occupational safety issues throughout the construction life cycle projects, avoiding hazards and risks and, consequently, increasing safety. This work investigates BIM methodology and related technologies application for building safety planning in construction and demonstrates the potential of this technology for the integrated implementation of safety measures during the design phase and the construction site management. The first step consisted of a literature review on the application of BIM in safety in the design and planning phases. Following, to show the potentialities of construction simulation, a case study based on BIM 4D to prevent falls from height was developed. With BIM 4D, it is possible to follow the construction process over time, giving the construction safety technicians', designers, supervisors and managers the capability to analyse, in each phase, the potential risks and which safety measures should be implemented. BIM can effectively integrate safety measures from the design phase to the construction and use phase and do integrated safety planning within construction planning, leading to reliable safety management throughout the construction process.
\end{abstract}

Keywords: Building Information Modelling, Construction safety, Planning, Safety Elements, Construction Site Management; Falls from height.

\section{Introduction}

Technological developments have occurred in different sectors of activity over the last decades. Nevertheless, in the Architecture, Engineering and Construction (AEC) sector, new technologies in the design, planning and construction phases have not been fully implemented by integrating safety measures in the process [1].

Around the world, only the most competitive and efficient companies are successful in the construction market. Therefore, to have solid growth, it is essential to meet requirements regarding quality and safety.

According to 2019 Eurostat data, construction was the sector with the highest rate of non-fatal accidents at work among all economic activities, and it had the third-highest rate for fatal accidents between 2011 and 2017. These statistics confirm that this sector is both dangerous and lacks the tools for the reliable identification and integration of safety factors. Those figures also reveal that the methodologies currently used are not very effective in reducing the number of occupational accidents in construction.

Construction planning, supported by 2D drawings and schedules to describe safety needs at the worksite, has significant constraints in identifying hazards and implementing safety measures. The traditional approach requires engineers and architects to detect the potential hazards and determine the necessary safety procedures based on their experience. However, this planning process is complex because of the dynamic nature of construction projects and the consequent frequent changes in the safety needs of diverse worksites [2]. 
Building Information Modeling (BIM) is a collaborative work methodology that can be implemented across all the life cycles of a building, supporting the design, construction and project management through accurate virtual models. BIM is currently considered one of the most promising developments in the AEC sector, envisaging a full transition to the digitalization of the construction industry [3]. Within BIM, it is possible to integrate design and construction, contributing to the higher functional performance of buildings reducing costs and duration, achieving more sustainable results and higher-quality buildings, increasing safety at the construction sites [4], and the efficiency of project management [5]-[7].

BIM is a holistic concept comprising technologies and processes to manage project data in a digital format throughout projects' life cycles [8]. It is an integrated process for digitally exploring projects' critical physical and functional characteristics before the onsite building process, helping to deliver projects faster and more economically while minimising environmental impact, occupational safety hazards and consequent risks. Furthermore, coordinated and consistent information produces innovative design, better visualisation and simulation of real-construction conditions [9], estimation of performance and costs, and the creation of more accurate documentation [10], as well as resource planning, management and monitoring [9].

Parametric modelling speed up the model generation and modification allows conflict detection and assessment during the design phase to solve the detected problems in time, before the execution phase [11], [12]. BIM visualization and construction simulation assist in the site planning, resources and material supply planning and budgeting, permitting to achieve the best construction plan supported by an efficient collaboration among participants throughout the Project life cycle [13], [14].

The interest in using BIM methodology in the AEC sector has grown, especially regarding integrating safety measures throughout the building's life cycle. In addition, technological advances in BIM have led to the development of proactive safety solutions to plan and manage worksites [15].

This work started with the research question: what contribution can digital tools, such as BIM methodology, give to the integrated planning and management of safety in construction? To answer this question, researchers carried out a literature review. They also developed a case study using three software packages: Autodesk Revit, Microsoft Excel, and Autodesk Navisworks. It was developed a 4D BIM model using overlapping results from the three software to analyse the suitability of the 3D model, the safety measures applied to it and the possible onsite use.

This study's main purpose is to promote actions to improve safety in the AEC sector and encourage the integration of safety measures earlier in the design process, not only in large Projects but also in common ones. Safer worksites also contribute to higher worker satisfaction and motivation and reduced labour costs because of fewer occupational accidents.

This work demonstrates the potential of BIM methodology to implement safety measures from design to construction planning through construction site management to contribute to a Lean Construction approach.

\section{Building Information Modelling for Construction Safety Management}

The social, economic and financial impact of construction Projects leads to highlight the particular focus that should be done to the on-time completion, being effective scheduling vital to plan and control the various processes and time-oriented events along with the Project phases, and consequently, a crucial success factor in managing and evaluating the performance of the Project [16]. The incorrect or inefficient construction planning negatively impacts the construction site's productivity and safety performance [17].

BIM as a collaborative management platform based on the BIM model can optimize the construction plan, produce management procedures, and improve the efficiency of 
construction management measures. BIM can contribute to easier schedule control, quality control, and safety control and improve the degree and efficiency of management information [18]. Nowadays, it is also applied to managing project supervision quality, progress, cost, and safety in engineering projects [19].

Research studies show that BIM methodology can be successfully applied to occupational safety planning and accident prevention [20]-[25]. The occupational risks monitoring capabilities were identified using BIM design, BIM 4D simulation, rules algorithms, Virtual Reality (VR) based visualisation and hazard identification, and design for safety with BIM authoring tools [26]. Other authors also identified the Prevention through Design (PtD) [26-28], VR [29]-[31], Geographic Information Systems (GIS) [27, 29, 31], and BIM 4D [1, [32-35] for the occupational risk prevention in the design and planning phases. It is recognized the BIM earlier potentialities of hazard identification, analysis and prevention both in design and construction phases [36-39]. The BIM 3D models and the BIM $4 \mathrm{D}$ construction scheduling simulation allow a detailed, deep and clear understanding of site conditions and all the construction phases by analysing the site environmental factors and the visualization of the different project risks [41]. Thus, it is used for risk assessment enabling designers and contractors to identify hazards, design and schedule errors, select design alternatives concerning safety in the early design phase and visualise the 4D model for site safety planning [36]. Several authors [2], [42] studied the automation of the fall from height hazards prevention through BIM methodology using collective protection measures, especially in slabs boundaries. Aiming to improve project management, 4D BIM was applied through which managers can visualize, assess and prevent project risks throughout the life cycle of a construction project [43].

Construction site simulation can also be integrated with "toolbox" meetings to analyse and discuss activities before starting [20]. It is recognized that BIM enables construction safety management improvement conjugating and overlaying different tools: online databases, virtual reality, overlaid 4D schedules [30].

The presented literature review concludes that different digital technologies and methodologies in the scope of construction risks' prevention are growing. 4D BIM is one of the most used integrating scheduling, risk assessment and consequent prevention, contributing to integrated and safe construction management. This study aims to enhance the advantages of 4D BIM to improve the construction Project safety management along its life-cycle in a reinforced concrete structure. It presents a construction management methodology to make occupational risk prevention reliable and integrated with the construction planning through 4D BIM, feasible in large projects and common ones.

\section{Methodology}

To understand digital technologies as they are applied to the design and planning phases, the literature review found and identified the most commonly used digital technologies in the area of safety in construction being the 4D BIM, one of the most used when the aim is to integrate scheduling with risk assessment and prevention and with construction management.

A case study was developed to show the potentialities of construction simulation and present, highlight, and explain the implemented modelling process phases. For the case study, researchers selected the BIM 4D technology, used primarily in the project planning phase based on the design of a Radiotherapy Centre. Researchers developed architectural and structural 3D models in Autodesk Revit software and applied safety measures to each model to avoid risks throughout the entire construction phase. For the construction planning, site routes and traffic directions were defined as well as temporary structures such as guardrails, scaffoldings, platforms, opening coverings and site fences [1].

The 4D BIM model was developed using Autodesk Navisworks software. In the time component (4th dimension), construction planning using Microsoft Excel was incorporated. With this integration, it was possible the simulation of the building evolution over 
time. Safety measures to be implemented have been incorporated in this fourth dimension through links to safety instructions.

\section{Case Study}

Researchers performed an in-depth analysis of the Radiotherapy Centre's design through AutoCAD (2D) architecture and structural design. The building consists of two floors: A basement and a ground floor. The basement is wholly buried with a structure composed of reinforced concrete walls around the entire perimeter to support the soil and prevent radiation propagation to the surrounding areas. In addition, researchers prepared documents containing the operating instructions and the safety measures (safety files/instructions) for the construction phase.

In preparing the documents, it was given special attention to the assembly/disassembly of temporary structures like scaffolding and guardrails. The next step was to develop the respective 3D models in Revit. They allowed the application of safety measures, emphasising the use of temporary structures. External online libraries (Revit City, Bim-store, BIMobject and BIM \& CO) were used to import objects such as scaffolding, platforms and construction fences.

Despite significant research on the use of such objects, few were available in these libraries. The researchers developed some families, including guardrails with a clamping system, guardrails with a spike system and hole covers (see figures of the families in Table 1 and 2).

For guardrails, researchers developed the two families with two different templates. First, the Metric Generic Model template was used for the vertical element through the command extrusion. Then, they imported this element into the Metric Generic Model Line Based template in a second phase.

The Metric Generic Model template was sufficient for the hole covers, by defining the parameters resulted in the generic model represented (see figure in Table 2). All of the defined safety elements can be incorporated into the 3D BIM models.

The safety elements incorporated into the structural model included two families of guardrails, hole covers, routes/traffic directions and the site fence (Fig. 1). In addition, the scaffolding and the working platform at height were used (Fig. 2). This distinction among the safety elements was necessary because of their differentiated use throughout the construction phases. Finally, the two 3D models were overlapped in Navisworks, generating a federated model (Fig. 3).

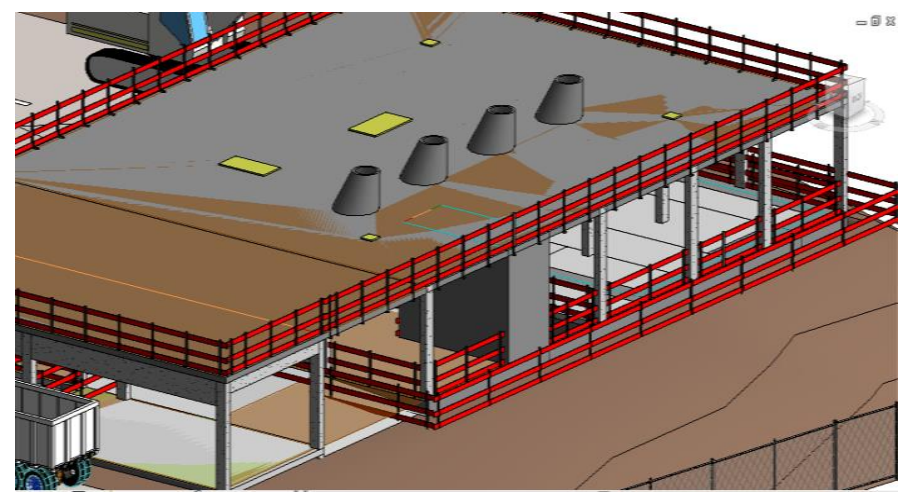

Figure 1. The structural 3D model with safety elements 


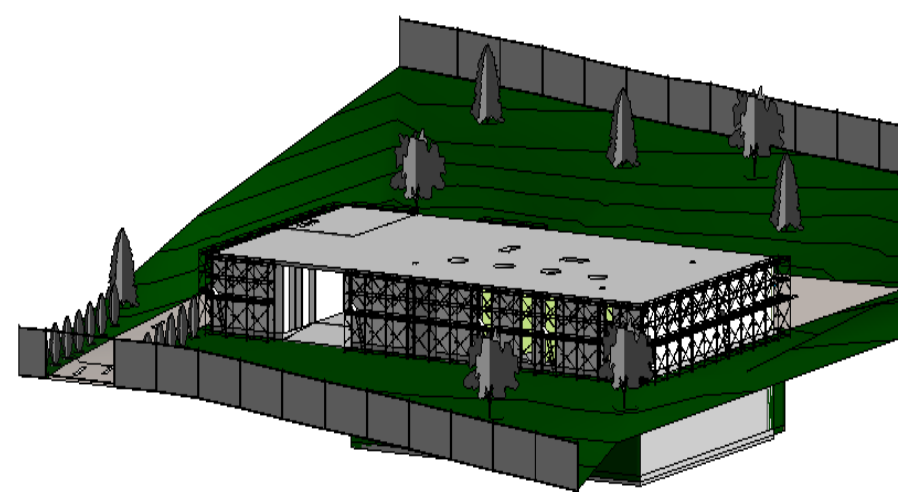

Figure 2. Architecture 3D model with safety equipment

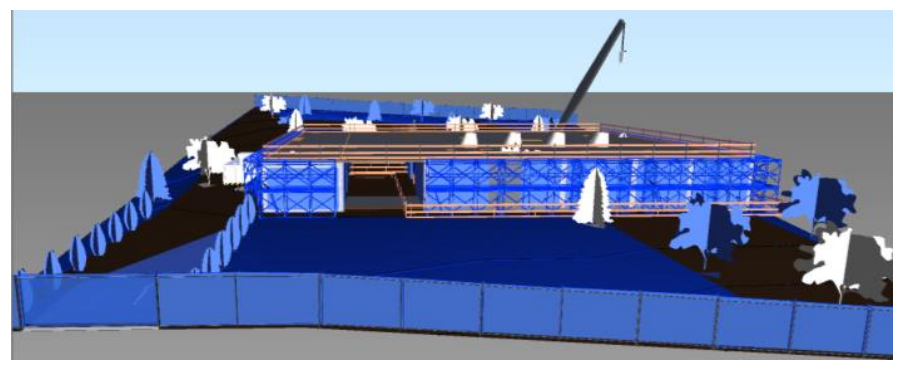

Figure 3. Federate model using Navisworks software

The 4D model was created by adding the time component to the Navisworks federated model. The time component was generated from the activity schedule developed in Microsoft Excel. This schedule considered the main construction activities and the temporary tasks, which correspond to the use of safety systems and the expected beginning and end for each task. To achieve a realistic definition of the work sequence, there should be a thorough understanding of the activities behind the entire schedule. Throughout the planning phase, designers must give critical thought to the timing of the placement and removal of temporary structures and safety elements since they remain for different periods at the worksite.

Researchers inserted tools like comments and links within the 4D model to reinforce safety, add information on temporary tasks and point out the need to consult safety files/instructions about the assembly/disassembly of scaffolding and guardrails (Fig. 4). These documents provide detailed descriptions of the assembly/disassembly of scaffolding and guardrails, hazards, risks and preventive measures.

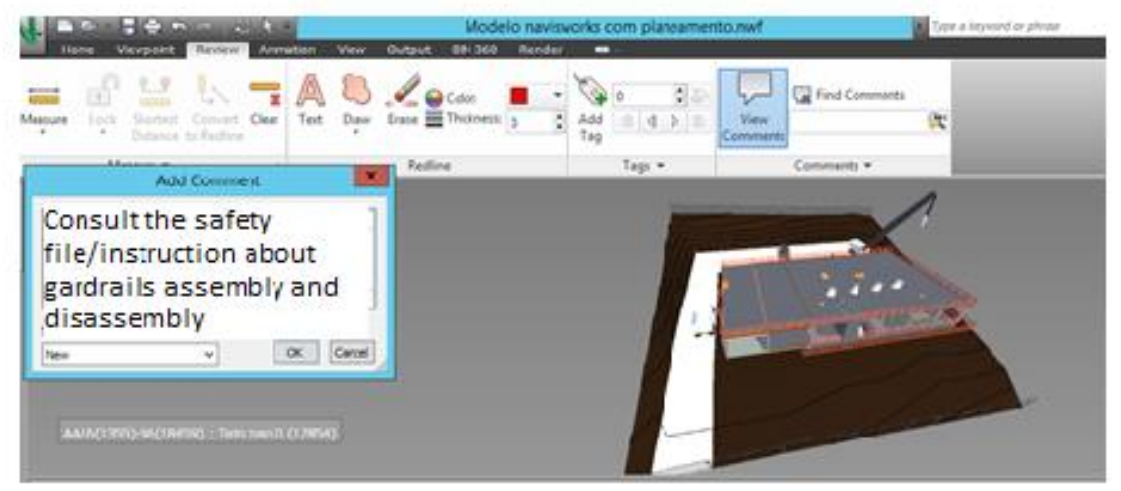

Figure 4. Links to safety guardrails for assembly/disassembly

Associating tasks with the planned schedule created a 4D simulation to follow the work requirements regarding safety during the entire construction project. Applying the 
Navisworks simulation tool to the 4D model made it possible to track the worksite development over time and to determine, at each moment, necessary safety interventions and management need visually. Navisworks simulation of the 4D model produced a colourcoded graphic in which each colour is associated with a type of task. Each task type has the following graphic meanings:

- Construction: when the task starts, the elements referring to the task are displayed in green, and upon completion, their colour turns to the colour of the Revit model.

- Demolish: at the task beginning, the elements to demolish are denoted with the colour red and disappear at the end.

- Temporary: for temporary structures, the elements are coloured yellow and disappear on the defined date.

Figure 5 illustrates the simulation of some of the construction phases with a colour-coded explanation.

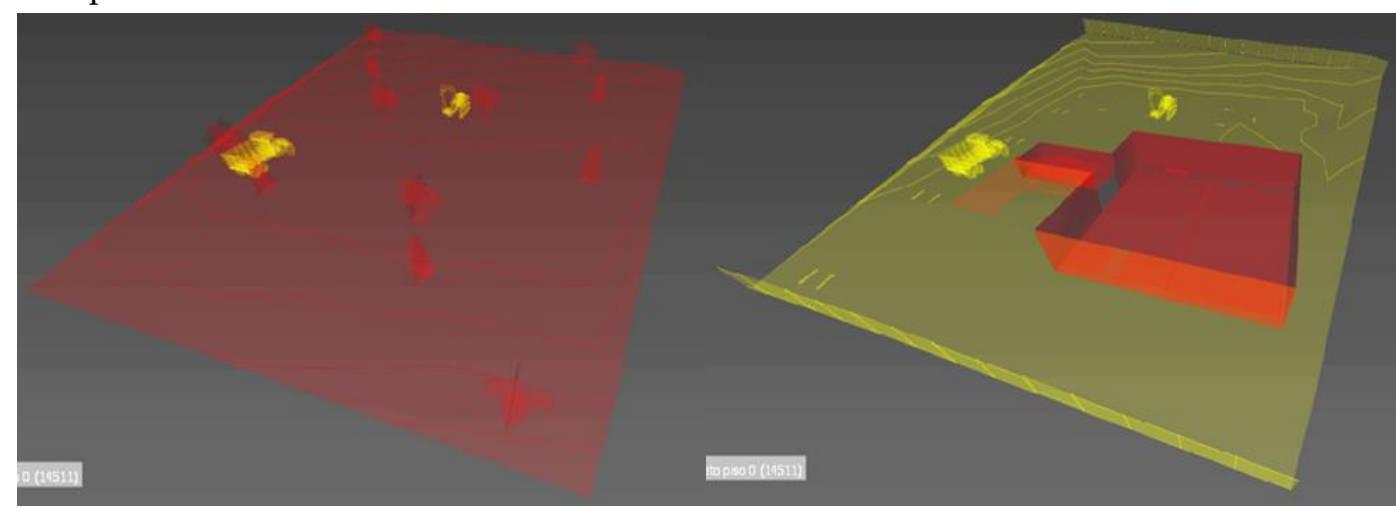

a) Construction site preparation

b) Excavation and fencing of the construction site

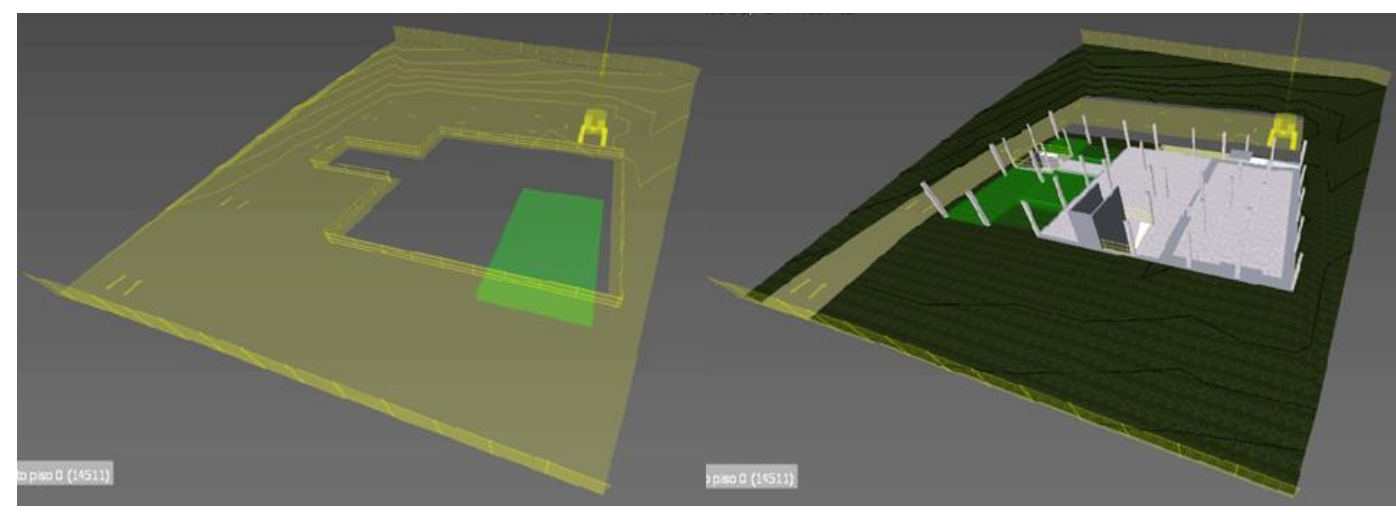

c) Guardrails placement in the excavation zone

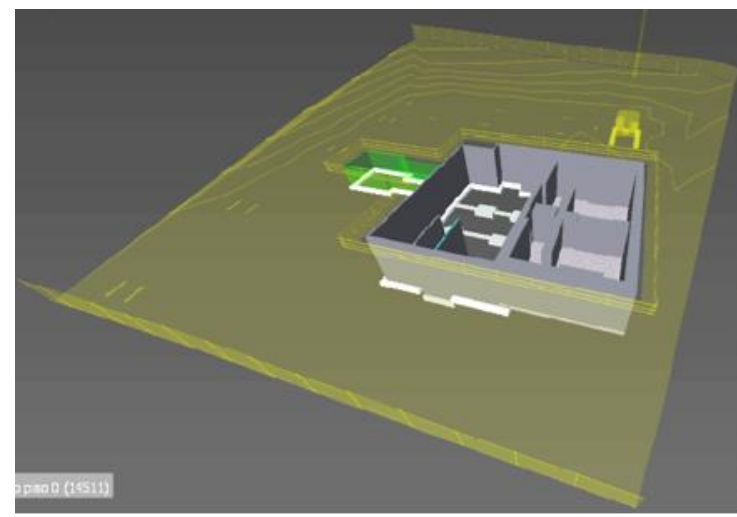

e) -1 structure and guardrails placement on the 0-floor level d) Structure of -1 floor

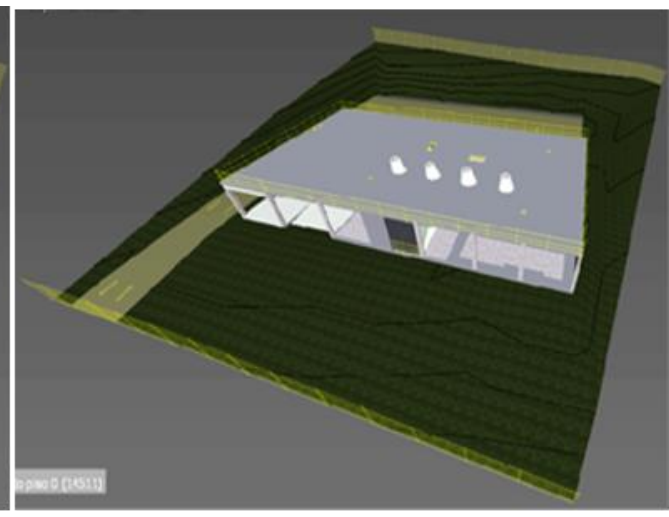

f) Placement of guardrails on the flat roof 


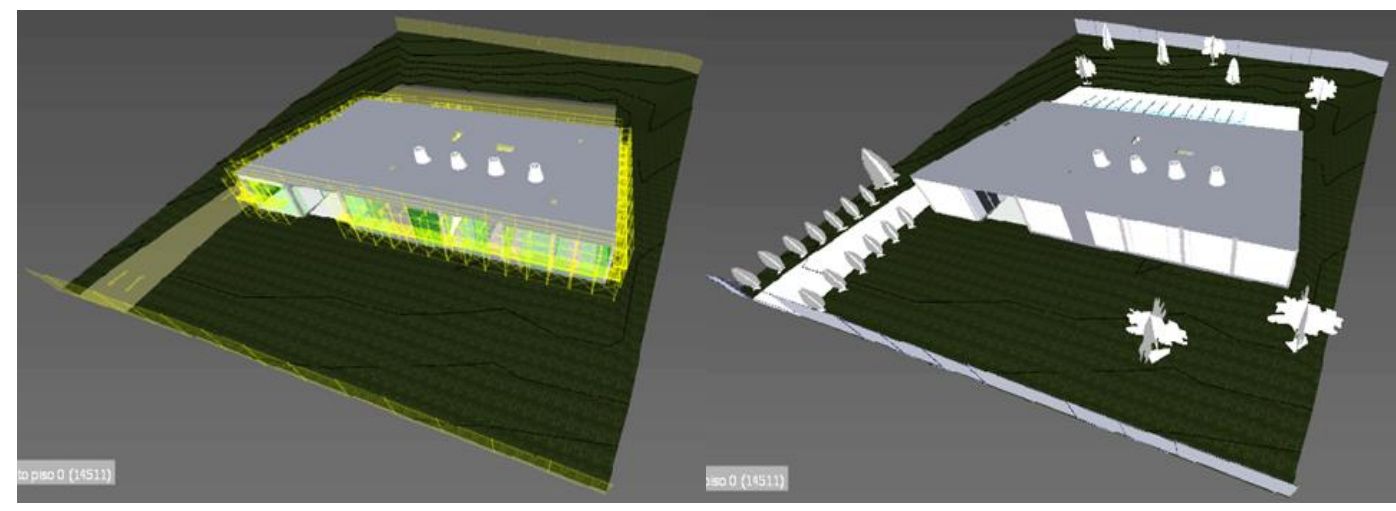

g) Scaffolding and exterior walls execution

h) Completed building

Figure 5. Case study $4 \mathrm{D}$ simulation

Figure 5 colours code explanation: ing.

a) Construction site preparation phase. The soil is coloured red because of earthmov-

b) Excavation and fencing of the construction site. The topography appears in yellow because it changed during the construction process. The excavation zone is coloured red because of the soil extraction. The fence is a temporary structure, so it is coloured yellow.

c) Guardrails Placement in the excavation zone. Because these elements are temporary structures, they are a yellow colour.

d) Structure of -1 floor. The completed concrete structure, to that phase, has the final colour of the project (colour of the Revit model).

e) Waterproofing of -1 floor and guardrails on floor 0 . These temporary elements are represented in yellow.

f) Placement of guardrails on the flat roof. These temporary elements are represented in yellow.

g) Placement of scaffolding and execution of exterior walls. The scaffolding is coloured yellow, and the exterior walls during construction are green.

h) Completed building. All of the work was concluded, and the final elements correspond to the colours of the graphic model in Revit.

\section{Results}

\subsection{Technologies}

The literature review verified that stakeholders manage safety throughout three phases of a building's life-cycle: design/planning, construction, and maintenance. The framework proposed by [40] prescribes a long-term risk management strategy and a process that allows stakeholders to work collaboratively to manage risks throughout the project life cycle. This Risk Mitigation Model developed by [40] demonstrates that the risk mitigation process should be implemented as early as possible, especially during the design or planning phase and that most risks should be "designed out" during the planning and design phases, leaving only the management of residual risks in the construction and subsequent phases.

Planning for safety in the early stages of a project contributes to a considerable decrease in risks, as exposed by the literature review that shows several digital tools developed for use in the design and construction phase to accurate occupational risks prevention.

\subsection{Design phase}

In the design phase, the Prevention through Design (PtD) methodology addresses occupational safety to prevent or minimise the hazards and risks associated with all 
phases of a building's life-cycle, whether in the construction, manufacture, use, or maintenance [26], [44]. The fundamental effort in promoting PtD is to improve communication and coordination among stakeholders. This change is expected to fill the gap between the design and construction phases. However, this change is not sufficient to minimise hazards and risks. Another approach involves conducting a thorough risk assessment of each design component. This assessment usually involves using various tools such as safety manuals, checklists, and software to help designers access construction safety knowledge. Technological advances allow designers to check building plans against building codes [44] automatically, and researchers are currently performing semantic research enrichment of Building Information Models to support automated checking of code compliance [45].

Ideally, a PtD software tool should help designers during the design phase, informing them of alternative design options and the safety consequences of various solutions. Furthermore, the tool should be capable of minimising risks, detecting and correcting for safety by default. By performing these functions, a PtD tool would provide appropriate safety knowledge at the right time, improving safety in the design phase [46]-[48] [48].

However, most risk identification and mitigation of potential construction hazards rely on the designer's competence. If designers do not have the knowledge or competence to deeply identify hazards and understand the construction tasks, sequence, and coordination, they cannot eliminate/minimise hazards and improve occupational safety [50].

\subsection{Planning phase}

As BIM provides an accurate design model and details on the resources required, it provides the basis for improved planning and scheduling of subcontractors, helping to ensure the people, equipment, and materials arrive at the proper time to reduce the waste of time and to facilitate better collaboration at the worksite [4]. This control permits designers to implement Lean construction techniques [51], reducing occupational accidents.

As one of the phases that most contribute to risk reduction, construction planning was highlighted, where designers and stakeholders have made an essential investment in improving safety conditions [40]. However, despite the availability of technologies that can assist in this process, designers still plan most construction projects manually [52].

The technologies of BIM 4D, among others, are helpful for the planning phase. This technology adds construction planning information to a 3D model, establishing a clear visualisation of construction sequences. The application of BIM 4D also improves the safety and health management of the construction process [52, 53]. For safety applications, BIM 4D consists of establishing a comprehensive 4D model that combines all project data on construction objects, processes, activities and sequences and conducting a risk analysis based on the developed model [40], allowing the occupational risks assessment and prevention [44].

\subsection{Modelling}

Guardrails with a clamping system, guardrails with a spike system and hole covers, leaving were modelled as the sharing parameters information for further quantification. It was possible to automatically extract the maps of quantities needed for safety equipment management from these families models. Tables 1 and 2 depict some information about these quantity take-offs. The automatic quantities take-off is an important part of safety management and construction management as a whole.

It was not possible to extract data from the remaining elements, such as scaffolding and fences, once their families were not designed to share information at that level. Therefore, when working with families of elements that do not exist in the Revit library and when using external libraries, these families may not provide the necessary information to effectively design for the project's needs. Thus, designers must be aware of the parameterization used in modelling new families and the use of families designed by other authors (with shared or non-shared parameters). 
Table 1. Maps of quantities - guardrails hole covers (extract)

\begin{tabular}{|c|c|c|c|c|c|}
\hline Type & Figure & $\begin{array}{c}\text { Length } \\
(\mathrm{mm})\end{array}$ & $\begin{array}{c}\text { Bar } \\
\text { Spacing } \\
(\mathrm{mm})\end{array}$ & $\begin{array}{c}\text { N.. of } \\
\text { Bars }\end{array}$ & $\begin{array}{c}\text { Slab } \\
\text { Thickness (mm) }\end{array}$ \\
\hline $\begin{array}{c}\text { Guardrails } \\
\text { with clamping } \\
\text { system }\end{array}$ & 4197 & 1500 & 3 & 200 \\
\hline $\begin{array}{c}\text { Guardrails } \\
\text { with spike } \\
\text { system }\end{array}$ & 4260 & 2000 & 2 & -- \\
\hline
\end{tabular}

Table 2. Maps of quantities - hole covers (extract)

\begin{tabular}{|c|c|c|c|c|c|c|c|}
\hline Level & Type & Figure & $\begin{array}{l}\text { With } \\
(\mathrm{mm})\end{array}$ & $\begin{array}{l}\text { Length } \\
(\mathrm{mm})\end{array}$ & $\begin{array}{l}\mathrm{Tab} \\
(\mathrm{mm})\end{array}$ & $\begin{array}{c}\text { Lower } \\
\text { Thickness } \\
(\mathrm{mm})\end{array}$ & $\begin{array}{c}\text { Upper } \\
\text { Thickness } \\
(\mathrm{mm})\end{array}$ \\
\hline Floor 0 & $\begin{array}{c}\text { Cover } \\
2400^{*} 1500\end{array}$ & & 1700 & 2600 & 100 & 50 & 50 \\
\hline \multirow{3}{*}{ Ceiling } & $\begin{array}{c}\text { Cover } \\
300 * 300\end{array}$ & & 500 & 500 & 100 & 50 & 50 \\
\hline & $\begin{array}{c}\text { Cover } \\
1800^{*} 800\end{array}$ & & 1000 & 2000 & 100 & 50 & 50 \\
\hline & $\begin{array}{c}\text { Cover } \\
2000^{*} 989\end{array}$ & & 1189 & 2200 & 100 & 50 & 50 \\
\hline
\end{tabular}

\section{Discussion}

With the ability to incorporate comments and links in the BIM 4D model and the capacity to quantify safety elements, construction safety technicians, designers, supervisors and managers have at their disposal a complete set of safety tools in a global work methodology integrated into a single computer tool. In advance, it is possible to identify the safety measures that need to be implemented during the entire construction period by following the simulation and consulting the safety documents integrated into the model simultaneously. In the present case study, it was possible to analyse the evolution of the project's implementation and quantify the needs for guardrails and hole covers during the entire construction phase. This approach allowed to obtain all necessary quantity maps for construction management.

The model and its virtual simulation are also excellent tools to provide professional training. It is possible to have, simultaneously, an overview and a detailed view of the whole construction process and the safety measures that should be applied at each stage. In addition to simplifying the work of the designers, this approach can be used in the daily grind in the construction site, allowing the reinforcement of the safety culture.

Some Revit families regarding safety at work are missing from the BIM libraries, so it was necessary to model some safety objects (guardrails and hole covers). This omission demonstrates how safety remains a secondary concern even in digital technologies compared with other project specialities. 
More detailed work planning and more information available for 4D BIM model simulation bring possible greater control over the worksite. Another feature of the BIM methodology is that changes made directly to the 3D model are automatically updated to the $4 \mathrm{D}$ model. In this way, the loss of information is avoided. This automatic updating effectively improves communication among stakeholders throughout the construction process, avoiding delays in the timely detection of project changes and/or in planned tasks, thereby avoiding errors and improving construction management quality.

Using this methodology makes the safety management integrated with the whole project management, a more efficient process and avoiding opportunities for unforeseen events. Its use will also contribute to reducing workplace accidents and implementing safety procedures more efficiently.

This case study confirms the complexity of preparing the models and the advantages of BIM methodology in preventing occupational risks in any construction project.

\section{Conclusions}

The AEC sector has been developing advanced technologies to achieve higher quality, productivity and safety levels. However, using these types of tools requires an excellent understanding of their capabilities. In addition, the designers and other stakeholders also often lack training in identifying hazards and implementing safety measures.

This paper demonstrates the importance of a collaborative and integrated methodology from the design, planning, construction until the use phase aiming the effective occupational risk prevention and safety planning. It also highlights and shows that using new methodologies, such as BIM, can optimise construction processes, making it possible to plan effective safety measures in space and time through 4D BIM simulations, with realtime control and work planning knowledge. Furthermore, BIM methodology fills gaps in the traditional methods (2D) by gathering diverse information in one model, updating changes to the model automatically and providing rapid, digital communication among all the stakeholders of the construction project and permitting the planning of the production processes considering in simultaneous the occupational risk assessment and the correspondent safety measures.

Compared with the widely used 2D approach, 4D models enable faster visualisation and perception of work developments and safety needs, allowing quicker and more reliable decision-making. The literature review highlights that the $4 \mathrm{D}$ model permits an integrated and reliable identification and prevention of occupational risks.

Being construction a continuous process, there should be no gaps between the different phases regarding safety. With the growing complexity of construction projects and the requirement for their fast completion, the occupational risks related to their implementation in the field are also increasing. Accidents are high economic and social costs that must be avoided. Thus, safety procedures require investments that must be accounted for in the construction process budget. Coordination of safety procedures at all stages requires adopting solutions in planning, design, execution, and good communication between stakeholders throughout the process. The construction management methodology presented led to making occupational risk prevention reliable and integrated with the construction planning through 4D modelling not only in large and complex projects but also in common ones.

The following research develops a 4D integrated approach including construction activities, safety, works planning, procedures automatic production, using the last planner system methodology.

Author Contributions: Conceptualization and methodology D.P., F.R.; investigation D.P., F.R.; writing-original draft preparation D.P., F.R.; F.R., J.S.B writing - review and editing; supervision, F.R. and J.S.B. All authors have read and agreed to the published version of the manuscript.

Funding: This research received no external funding.

Conflicts of Interest: The authors declare no conflict of interest 


\section{References}

[1] D. Pinto, F. Rodrigues, and J. Santos Baptista, “The contribution of digital technologies to construction safety," in International Symposium on Occupational Safety and Hygiene, Ed. CRC Press/Balkema, Ed. London: Ed. CRC Press/Balkema, 2018, pp. 115119.

[2] S. Zhang, K. Sulankivi, M. Kiviniemi, I. Romo, C. M. C. M. Eastman, and J. Teizer, “BIM-based fall hazard identification and prevention in construction safety planning," Saf. Sci., vol. 72, pp. 31-45, Feb. 2015, doi: 10.1016/j.ssci.2014.08.001.

[3] E. A. Pärn and D. J. Edwards, "Conceptualising the FinDD API plug-in: A study of BIM-FM integration," Autom. Constr., vol. 80, pp. 11-21, Aug. 2017, doi: 10.1016/j.autcon.2017.03.015.

[4] R. Sacks, C. M. Eastman, G. Lee, and P. Teicholz, BIM Handbook: A Guide to Building Information Modeling for Owners, Designers, Engineers, Contractors and Facility Managers. John Wiley and Sons, Hoboken, NJ., 2018.

[5] Y. Y. Al-Ashmori et al., "BIM benefits and its influence on the BIM implementation in Malaysia," Ain Shams Eng. J., vol. 11, no. 4, pp. 1013-1019, Dec. 2020, doi: 10.1016/J.ASEJ.2020.02.002.

[6] M. Jiang, Y. Cheng, T. Lei, and Z. Liu, “'intelligent Construction, Digital Modeling of the Future' Internet + BIM Service EPC Project - Take the Exhibition Center of National Cybersecurity Center for Education and Innovation Project as an Example," in IOP Conference Series: Earth and Environmental Science, Vol. 719, nº 2, Article ID 022043, 2021, vol. 719, no. 2, doi: 10.1088/17551315/719/2/022043.

[7] Z. Li, “The Application of BIM Technology in the whole Life Cycle of Construction Project," IOP Conference Series: Earth and Environmental Science, vol. 510, no. 6. 2020, doi: 10.1088/1755-1315/510/6/062004.

[8] B. Succar, "Building information modelling framework: A research and delivery foundation for industry stakeholders," Autom. Constr., vol. 18, pp. 357-375, 2009, doi: 10.1016/j.autcon.2008.10.003.

[9] S. Tang, D. R. Shelden, C. M. Eastman, P. Pishdad-bozorgi, and X. Gao, “A review of building information modeling (BIM) and the internet of things (IoT) devices integration : Present status and future trends," Autom. Constr., vol. 101, no. January, pp. 127-139, 2019, doi: 10.1016/j.autcon.2019.01.020.

[10] K. Dispenza, “The Daily Life of Building Information Modeling (BIM) - Buildipedia,” 2010. .

[11] K. F. Chien, Z. H. Wu, and S. C. Huang, "Identifying and assessing critical risk factors for BIM projects: Empirical study," Autom. Constr., vol. 45, pp. 1-15, Sep. 2014, doi: 10.1016/J.AUTCON.2014.04.012.

[12] L. Liao and E. A. L. Teo, “Critical Success Factors for enhancing the Building Information Modelling implementation in building projects in Singapore," J. Civ. Eng. Manag., vol. 23, no. 8, pp. 1029-1044, Nov. 2017, doi: 10.3846/13923730.2017.1374300.

[13] S. Azhar, "Building information modeling (BIM): Trends, benefits, risks, and challenges for the AEC industry," Leadersh. Manag. Eng., vol. 11, no. 3, pp. 241-252, Jul. 2011, doi: 10.1061/(ASCE)LM.1943-5630.0000127.

[14] M. C. Georgiadou, "An overview of benefits and challenges of building information modelling (BIM) adoption in UK residential projects," Constr. Innov., vol. 19, no. 3, pp. 298-320, 2019, doi: 10.1108/CI-04-2017-0030.

[15] A. Enshassi, A. Ayyash, and R. M. Choudhry, “BIM for construction safety improvement in Gaza strip: awareness, applications and barriers," vol. 16, no. 3, pp. 249-265, Jul. 2016, doi: 10.1080/15623599.2016.1167367.

[16] V. Getuli, P. Capone, A. Bruttini, and S. Isaac, “BIM-based immersive Virtual Reality for construction workspace planning: A safety-oriented approach," Autom. Constr., vol. 114, no. February, p. 103160, 2020, doi: 10.1016/j.autcon.2020.103160.

[17] M. S. Dashti, M. RezaZadeh, M. Khanzadi, and H. Taghaddos, “Integrated BIM-based simulation for automated time-space conflict management in construction projects," Autom. Constr., vol. 132, p. 103957, Dec. 2021, doi: 10.1016/J.AUTCON.2021.103957.

[18] D. Miao, “Application of BIM Technology in the Informatization of Construction Management," pp. 613-621, 2022, doi: 10.1007/978-981-16-5854-9_78.

[19] H. Yang, L. Wang, and X. Jiang, “Dynamic control of integrated project management system based on engineering projects," 
Comput. Aided. Des. Appl., vol. 19, no. S4, pp. 90-101, 2022, [Online]. Available: scopus.com/record/display.uri?eid=2-s2.085111647944\&origin=resultslist\&sort=plf-f\&src=s\&sid=054d5190925940183795eb4cc48d481e\&sot=b\&sdt=b\&sl=46\&s=TITLEABS-KEY\%28BIM+and+safety+and+construction\%29\&relpos=3\&citeCnt=0\&searchTerm=.

[20] A. A. Ganah and G. A. John, “BIM and project planning integration for onsite safety induction," J. Eng. Des. Technol., vol. 15, no. 3, pp. 341-354, 2017, doi: 10.1108/JEDT-02-2016-0012.

[21] K. Kim, Y. Cho, and S. Zhang, "Integrating work sequences and temporary structures into safety planning: Automated scaffolding-related safety hazard identification and prevention in BIM," Autom. Constr., vol. 70, pp. 128-142, Oct. 2016, doi: 10.1016/J.AUTCON.2016.06.012.

[22] R. Takim, M. H. Zulkifli, and A. H. Nawawi, "Integration of Automated Safety Rule Checking (ASRC) System for Safety Planning BIM-Based Projects in Malaysia," Procedia - Soc. Behav. Sci., vol. 222, pp. 103-110, Jun. 2016, doi: 10.1016/J.SBSPRO.2016.05.195.

[23] P. A. Zadeh, G. Wang, H. B. Cavka, S. Staub-french, and R. Pottinger, "Information Quality Assessment for Facility Management," Adv. Eng. Informatics, vol. 33, pp. 181-205, 2017, doi: 10.1016/j.aei.2017.06.003.

[24] M. O. Fadeyi, “The role of building information modeling (BIM) in delivering the sustainable building value," Int. J. Sustain. Built Environ., vol. 6, no. 2, pp. 711-722, Dec. 2017, doi: 10.1016/J.IJSBE.2017.08.003.

[25] V. Getuli, S. M. Ventura, P. Capone, and A. L. C. Ciribini, "BIM-based Code Checking for Construction Health and Safety," Procedia Eng., vol. 196, pp. 454-461, Jan. 2017, doi: 10.1016/J.PROENG.2017.07.224.

[26] E. M. Wetzel and W. Y. Thabet, "The use of a BIM-based framework to support safe facility management processes," Autom. Constr., 2015, doi: 10.1016/j.autcon.2015.09.004.

[27] J. Qi, R. R. a. Issa, S. Olbina, and J. Hinze, “Use of BIM in Design to Prevent Construction Worker Falls,” J. Comput. Civ. Eng., vol. 28, no. 5, pp. A4014008-1-A4014008-10, Sep. 2014, doi: 10.1061/(ASCE)CP.1943-5487.0000365.

[28] S. Zhang, F. Boukamp, and J. Teizer, “Ontology-based semantic modeling of construction safety knowledge: Towards automated safety planning for job hazard analysis (JHA)," Autom. Constr., vol. 52, pp. 29-41, Apr. 2015, doi: 10.1016/j.autcon.2015.02.005.

[29] T. Cheng and J. Teizer, "Real-time resource location data collection and visualization technology for construction safety and activity monitoring applications," Autom. Constr., vol. 34, pp. 3-15, 2013, doi: 10.1016/j.autcon.2012.10.017.

[30] W. Zhou, J. Whyte, and R. Sacks, “Construction safety and digital design: A review," Autom. Constr., vol. 22, pp. 102-111, Mar. 2012, doi: 10.1016/j.autcon.2011.07.005.

[31] C.-S. S. Park and H.-J. J. Kim, “A framework for construction safety management and visualization system," Autom. Constr., vol. 33, pp. 95-103, Aug. 2013, doi: 10.1016/j.autcon.2012.09.012.

[32] V. K. Bansal, “Application of geographic information systems in construction safety planning," Int. J. Proj. Manag., vol. 29, no. 1, pp. 66-77, Jan. 2011, doi: 10.1016/j.ijproman.2010.01.007.

[33] B. Choi, H.-S. S. Lee, M. Park, Y. K. Cho, and H. Kim, “Framework for Work-Space Planning Using Four-Dimensional BIM in Construction Projects," J. Constr. Eng. Manag., vol. 140, no. 9, p. 04014041, Sep. 2014, doi: 10.1061/(ASCE)CO.19437862.0000885 .

[34] T. Sawyer, "Construction managers embrace 4D BIM for safety,” ENR (Engineering News-Record), vol. 272, no. 22, Jun. 2014.

[35] L. Chen and H. Luo, "A BIM-based construction quality management model and its applications," Autom. Constr., vol. 46, pp. 64-73, 2014, doi: 10.1016/j.autcon.2014.05.009.

[36] Z. Jin, J. Gambatese, D. Liu, and V. Dharmapalan, “Using 4D BIM to assess construction risks during the design phase,” Eng. Constr. Archit. Manag., vol. 26, no. 11, pp. 2637-2654, 2019, doi: 10.1108/ECAM-09-2018-0379.

[37] S. Zhang, J. Teizer, J. K. Lee, C. M. Eastman, and M. Venugopal, “Building Information Modeling (BIM) and Safety: Automatic Safety Checking of Construction Models and Schedules," Autom. Constr., vol. 29, pp. 183-195, Jan. 2013, doi: 10.1016/J.AUTCON.2012.05.006. 
[38] H. Malekitabar, A. Ardeshir, M. H. Sebt, and R. Stouffs, “Construction safety risk drivers: A BIM approach," Saf. Sci., vol. 82, pp. 445-455, Feb. 2016, doi: 10.1016/J.SSCI.2015.11.002.

[39] G. Hongling, Y. Yantao, Z. Weisheng, and L. Yan, “BIM and Safety Rules Based Automated Identification of Unsafe Design Factors in Construction," Procedia Eng., vol. 164, pp. 467-472, Jan. 2016, doi: 10.1016/J.PROENG.2016.11.646.

[40] Y. Zou, A. Kiviniemi, and S. W. Jones, “A review of risk management through BIM and BIM-related technologies," Saf. Sci., vol. 97, pp. 88-98, Aug. 2017, doi: 10.1016/j.ssci.2015.12.027.

[41] B. Hardin and D. McCool, BIM and construction management : proven tools, methods, and workflows. Indianopolis: Wiley, 2015.

[42] F. Rodrigues, F. Antunes, and R. Matos, "Safety plugins for risks prevention through design resourcing BIM," Constr. Innov., 2020, doi: 10.1108/CI-12-2019-0147.

[43] T. Hartmann, H. Van Meerveld, N. Vossebeld, and A. Adriaanse, "Aligning building information model tools and construction management methods," Autom. Constr., vol. 22, pp. 605-613, Mar. 2012, doi: 10.1016/J.AUTCON.2011.12.011.

[44] R. Jin, B. Zhong, L. Ma, A. Hashemi, and L. Ding, "Integrating BIM with building performance analysis in project life-cycle," Automation in Construction, vol. 106. 2019, doi: 10.1016/j.autcon.2019.102861.

[45] T. Bloch and R. Sacks, “Clustering Information Types for Semantic Enrichment of Building Information Models to Support Automated Code Compliance Checking," J. Comput. Civ. Eng., vol. 34, no. 6, p. 04020040, 2020, doi: 10.1061/(asce)cp.19435487.0000922.

[46] J. Qi, R. R. A. Issa, S. Olbina, and J. Hinze, “Use of Building Information Modeling in Design to Prevent Construction Worker Falls," J. Comput. Civ. Eng., vol. 28, no. 5, p. A4014008, Sep. 2014, doi: 10.1061/(ASCE)CP.1943-5487.0000365.

[47] F. Rodrigues, J. Estrada, F. Antunes, and P. Swuste, “Safety Through Design: A BIM-Based Framework," Springer, Cham, 2018, pp. 112-123.

[48] F. Rodrigues, F. Antunes, and R. Matos, "Safety plugins for risks prevention through design resourcing BIM," Constr. Innov., vol. 21, no. 2, pp. 244-258, 2021, doi: 10.1108/CI-12-2019-0147.

[49] F. Rodrigues, F. Antunes, and R. Matos, “Safety Plugins for risks prevention through design resourcing BIM," Constr. Innov. Information, Process. Manag., vol. in press, 2020.

[50] M. R. Hallowell and D. Hansen, “Measuring and improving designer hazard recognition skill: Critical competency to enable prevention through design," Saf. Sci., vol. 82, pp. 254-263, 2016, doi: 10.1016/j.ssci.2015.09.005.

[51] R. Sacks, B. A. Dave, L. Koskela, and R. Owen, “Analysis framework for the interaction between lean construction and Building Information Modelling," Proc. IGLC17 17th Annu. Conf. Int. Gr. Lean Constr., pp. 221-234, 2009.

[52] M. Sheikhkhoshkar, F. P. Rahimian, M. H. Kaveh, M. R. Hosseini, and D. J. Edwards, “Automated planning of concrete joint layouts with 4D-BIM," Autom. Constr., vol. 107, p. 102943, Nov. 2019, doi: 10.1016/j.autcon.2019.102943.

[53] H. Golizadeh, C. K. H. Hon, R. Drogemuller, and M. Reza Hosseini, “Digital engineering potential in addressing causes of construction accidents," Automation in Construction, vol. 95. Elsevier B.V., pp. 284-295, Nov. 01, 2018, doi: 10.1016/j.autcon.2018.08.013.

[54] K. T. Pham, D. N. Vu, P. L. H. Hong, and C. Park, “4D-BIM-based workspace planning for temporary safety facilities in construction SMES," Int. J. Environ. Res. Public Health, vol. 17, no. 10, May 2020, doi: 10.3390/ijerph17103403. 